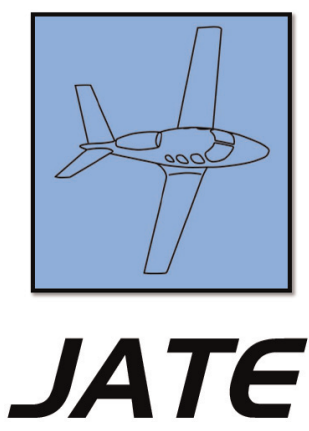

Journal of Aviation Technology and Engineering 4:2 (2015) 32-48

\title{
The Effects of Aircraft Certification Rules on General Aviation Accidents
}

\author{
Carolina L. Anderson \\ Embry-Riddle Aeronautical University
}

\begin{abstract}
The purpose of this study was to analyze the frequency of general aviation (GA) airplane accidents and accident rates on the basis of aircraft certification to determine whether or not differences in aircraft certification rules had an influence on accidents. In addition, the narrative cause descriptions contained within the accident reports were analyzed to determine whether there were differences in the qualitative data for the different certification categories. The certification categories examined were: Federal Aviation Regulations Part 23 (Part 23), Civil Air Regulations 3 (CAR 3), Light Sport Aircraft (LSA), and Experimental-Amateur Built (E-AB). The accident causes examined were those classified as: Loss of Control (LOC), Controlled Flight into Terrain (CFIT), Engine Failure, and Structural Failure. Airworthiness certification categories represent a wide diversity of government oversight. Part 23 rules have evolved from the initial set of simpler design standards and have progressed into a comprehensive and strict set of rules to address the safety issues of the more complex airplanes within the category. E-AB airplanes have the least amount of government oversight and are the fastest-growing segment. The LSA category is a more recent certification category that utilizes consensus standards in the approval process. CAR 3 airplanes were designed and manufactured under simpler rules, but modifying these airplanes has become lengthy and expensive.

The study was conducted using a mixed-methods methodology. A Chi-Square test was used for a quantitative analysis of the accident frequency among aircraft certification categories. Accident rate analysis of the accidents among aircraft certification categories involved an
\end{abstract}

\begin{abstract}
About the Author
Carolina Anderson earned her PhD in aviation from Embry-Riddle Aeronautical University in December of 2013. The title of her dissertation was The Effects of Aircraft Certification Rules on General Aviation Accidents. Dr. Anderson holds an MBA from Embry-Riddle Aeronautical University (2002) and a BS in mechanical engineering from Los Andes University in Bogotá, Colombia (1998). In addition, she holds the following professional certifications: Airline Transport Pilot Certificate; Certified Flight Instructor; Glider, Instrument and Multi-engine Ratings; Check Pilot and Training Center Evaluator (2004-2011) (Federal Aviation Administration). Dr. Anderson is an assistant professor of aeronautical science in the College of Aviation at Embry-Riddle Aeronautical University (ERAU; 2011 to present). Prior to joining the faculty at ERAU, she served as Training Manager for the Flight Department at ERAU, Standards Check-Pilot and Flight Instructor (2000-2011). Over the last five years, Dr. Anderson has been involved in numerous research projects, including the flight testing of biofuels for general aviation, the development and instruction of an Upset Recovery Training Course for FAA inspectors, the development and acquisition of flight test data for Level 6 Flight Training Devices (FTDs), as well as various projects for the FAA Center of Excellence for General Aviation Research (CGAR). Dr. Anderson participated in the Part 23 Aviation Rulemaking Committee and she is currently the vice chairman of the Industry Liaison Sub-Committee of the ASTM General Aviation Chapter (F44). Correspondence concerning this article should be sent to lenzc@erau.edu.
\end{abstract}

This article is based on the Doctoral Dissertation of Carolina L. Anderson, submitted to the Department of Doctoral Studies in partial fulfillment of the requirements for the degree of Doctor of Philosophy at Embry-Riddle Aeronautical University. 
analysis of covariance (ANCOVA) test. The qualitative component involved the use of text mining techniques for the analysis of the narrative cause descriptions contained within the accident reports.

The Chi-Square test indicated that there was no significant difference in the number of accidents among the different certification categories when either CFIT or Structural Failure was listed as cause. However, there was a significant difference in the frequency of accidents with regard to LOC and Engine Failure accidents. The results of the ANCOVA test indicated that there was no significant difference in the accident rate with regard to LOC, CFIT, or Structural Failure accidents. There was, however, a significant difference in Engine Failure accidents between $\mathrm{E}-\mathrm{AB}$ and the other categories.

The text mining analysis of the narrative causes of LOC accidents indicated that only the CAR 3 category airplanes had clusters of words associated with visual flight into instrument meteorological conditions. CAR 3 airplanes were designed and manufactured prior to the 1960s, and in most cases have not been retrofitted to take advantage of newer technologies that could help prevent LOC accidents.

The study indicated that GA aircraft certification rules do not have a statistically significant effect on aircraft accidents except for LOC and Engine Failure. According to the literature, government oversight could have become an obstacle in the implementation of safetyenhancing equipment that could reduce LOC accidents. Oversight should focus on ensuring that E-AB aircraft owners perform a functional test that could prevent some of the Engine Failure accidents.

Keywords: general aviation, certification, FAR Part 23, consensus standards, aircraft accidents

\section{Introduction}

Aircraft certification regulations are intended to ensure the airworthiness of aircraft by requiring manufacturers of aircraft and aircraft components to comply with approved aircraft designs, maintenance requirements, and operational limitations. The main objective of aircraft certification and continued airworthiness requirements is to increase the reliability of safety critical systems (Committee on Aircraft Certification Safety Management, 1998). While strict certification requirements represent high standards for aircraft manufacturers, in the last three decades new general aviation (GA) aircraft certification costs have increased, the number of GA aircraft produced has decreased and there have been no accompanying substantial changes in operational safety or accident rates (Bowles, 2010).

\section{Background}

The Federal Aviation Administration (FAA) regulations that govern today's aircraft are found in Title 14 of the Code of Federal Regulations (14 CFR) (FAA, 2013). Airworthiness and certification standards for airplanes in the normal, utility, and aerobatic categories with a maximum certificated takeoff weight of 12,500 pounds or less are contained within 14 CFR Part 23 (Part 23) regulations (FAA, 2013). Part 23 also includes multiengine airplanes in the commuter category with a maximum certificated takeoff weight of 19,000 pounds or less and a seating configuration, excluding pilot seats, of 19 or less.

Since the 1980s, the regulatory scope of Part 23 has been shifted to address more complex aircraft, placing an excessive burden on the certification of simpler aircraft (FAA, 2009). In 2009, the FAA began a Part 23 Certification Process Study (CPS) to assess the adequacy of the current certification and airworthiness standards processes (FAA, 2009). Following the recommendations of the CPS in August 2011, the FAA created a Part 23 Aviation Rulemaking Committee (ARC) (FAA, 2011b). The ARC was tasked with completely restructuring Part 23 and subdividing the category into tiers based on airplane performance and complexity, as opposed to the existing weight and propulsion classifications, thereby allowing the FAA to target the required regulations and oversight specifically to each tier as necessary (FAA, 2009, p. 15). Tasks for the ARC also included a rewrite of the regulations on a broad, general, and progressive level. The ARC meetings were concluded in January of 2013; the recommendations of the ARC were submitted to the FAA in May of 2013 (Pompeo, 2013), and a Notice of Proposed Rulemaking (NPRM) is expected to be issued in December of 2015 (FAA, 2011b). One of the recommendations from the ARC is to develop a set of industry consensus standards that will become the means of compliance for the certification approval process of the new Part 23 regulations (Part 23 Aviation Rulemaking Committee, 2012). As a result of the ARC meetings, a new GA aircraft certification chapter was created within an international consensus standards organization, American Standards for Testing and Materials (ASTM, n.d.), ASTM F44 (n.d.).

The use of industry consensus standards is consistent with Public Law 104-113, also known as the National Technology Transfer and Advancement Act of 1995 (NTTAA), signed by President Clinton in March 1996. The NTTAA encourages federal agencies in the U.S. to utilize standards developed by voluntary consensus standards bodies rather than government-unique standards, wherever possible. It also includes provisions that encourage federal agencies to partner with the private sector in the development of these standards to help improve the efficiency and effectiveness of government (National Technology Transfer and Advancement Act, 1996). 


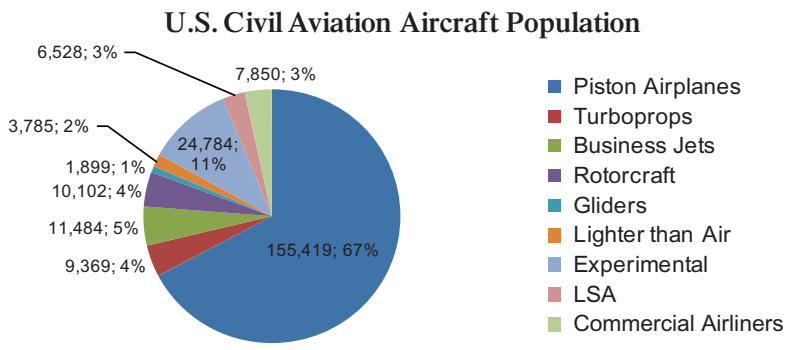

Figure 1. U.S. civil aviation aircraft population. Adapted from General Aviation Statistical Databook and Industry Outlook by GAMA (2012) and Small Airplanes by Bowles (2012).

In the early 2000s, GA advocacy groups, such as the Experimental Aircraft Association (EAA) and the General Aviation Manufacturers Association (GAMA), became concerned with rising certification costs and dwindling pilot populations. As a result, these advocacy groups petitioned the FAA to apply the NTTAA to an aviation case. In 2004, the FAA initiated a test case with the certification of a new aircraft category, Light Sport Aircraft (LSA), utilizing consensus standards (Bowles, 2010). Two categories within the LSA class were created: Special-Light Sport Aircraft (SLSA) and Experimental-Light Sport Aircraft (E-LSA). ASTM was chosen for the implementation and management of the LSA industry consensus standards. Early indicators show that this new category has been a success; thus, the propagation of consensus standards to more mainstream uses has become an appealing option applicable to other segments of aviation (FAA, 2009).

In the U.S., piston airplanes account for $67 \%$ of the total civil aviation aircraft population, followed by experimental airplanes at $11 \%$ (Figure 1). The number of piston airplanes manufactured annually has been decreasing substantially over the years. According to GAMA (2012), the U.S. produced 15,594 piston airplanes in 1947; however, only 1,514 piston airplanes were produced in 2012. The reduction in the number of aircraft produced represents a decline of over $90 \%$ (see Figure 2).
The decrease in piston airplane production in the U.S. from 1947 to 2012 can be attributed to many factors, such as: (a) the redistribution of the market share with the introduction of turbo-prop and jet airplanes, (b) the evolution of the product liability law, (c) natural disasters, (d) wars, (e) terrorist attacks, (f) economic downturns, (g) increasing fuel prices, and (h) rising certification costs (FAA, 2009; GAMA, 2012; Shetty \& Hansman, 2012).

Part 23-certified entry-level, two-seat and four-seat airplanes are essential in pilot flight training. The price of new entry-level airplanes has increased at a much higher rate than standard inflation (see Figure 3). According to the FAA (2009): "[a] consequence of the difficult regulatory environment has been the high cost of certification and a corresponding reduction of new entry-level products within part 23" (FAA, 2009, p. 15). The few new certified entry-level airplanes that are produced come at a very high cost due to the lengthy and expensive certification requirements. As a result, the existing flight training fleet of airplanes is composed of aircraft produced decades ago (GAMA, 2012). Retrofitting these old aircraft with new technologies would involve a lengthy and expensive recertification process, which inhibits many pilots from taking advantage of new technologies. Due to the stringent Part 23 regulatory requirements, these older aircraft designs cannot accommodate the new safety technologies that have become common, such as Ballistic Recovery Parachutes (BRS) and air bags (FAA, 2009). Over the last two decades, the U.S. active pilot population has been in decline, with an average decline of 10,000 pilots per year (GAMA, 2012).

A growing concern also exists about the number of active pilots in the U.S. In 2012, the U.S. had 188,001 private pilots, which represented over 100,000 fewer private pilots than in 1992. In 1992, the private pilot population was at 288,078 (GAMA, 2012). In 2012, the number of sport pilots increased $10.5 \%$ to 4,493 (see Figure 4), while the number of private pilots decreased at an average rate of 10,000 pilots per year (GAMA, 2012).

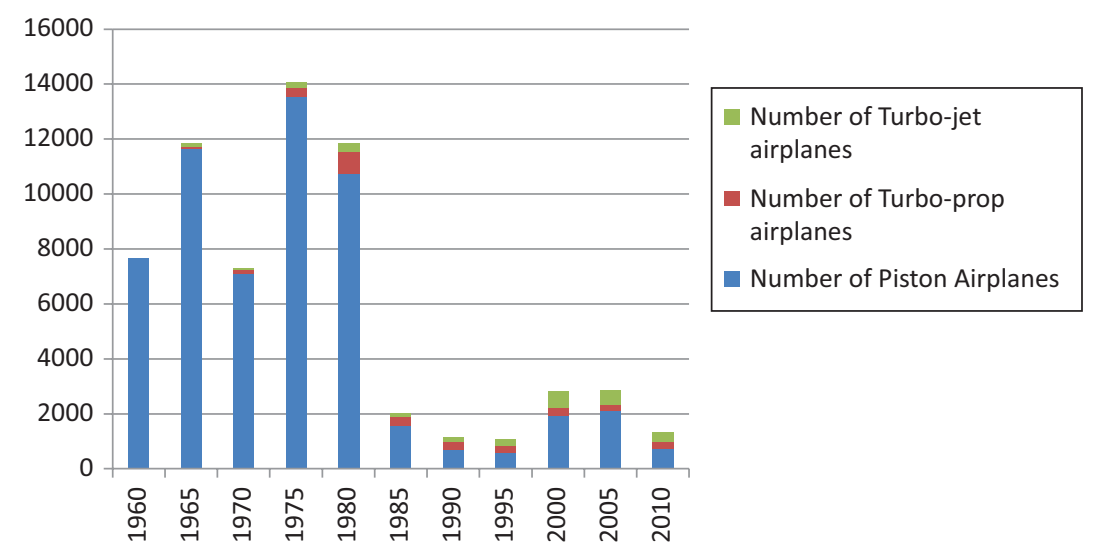

Figure 2. U.S. Part 23 airplanes manufactured annually. Adapted from General Aviation Statistical Databook and Industry Outlook by GAMA (2012). 


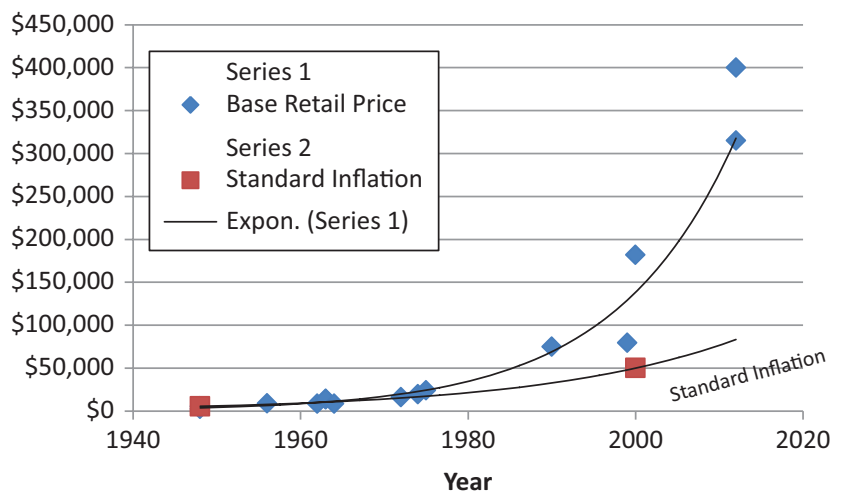

Figure 3. Four-seat entry-level airplane comparison.

Note: The airplane base retail prices in the chart are for the following airplanes in order from left to right: Cessna 170 in 1948, Aeronca Sedan in 1948, Cessna 172 in 1956, Maule M-4 in 1962, Mooney Master in 1963, Beech Musketter in 1963, Piper Cherokee in 1964, Gruman Cheetah in 1972, Beech Sundowner in 1974, Grumman Tiger in 1975, Socata Tampico in 1990, Cirrus SR-20 in 1999, Diamond Star in 2000, Cessna 172 in 2012, and Cessna 182 in 2012. Standard inflationary rates against \$5475 in 1948 were utilized. Adapted from presentation, Small Airplanes, by Bowles (2010).

As of 2013, there were 13 aircraft manufacturers of Part 23-certified two- or four-seat piston aircraft in the U.S. (GAMA, 2012); most of these Part 23 aircraft manufacturers have been in operation for over 30 years. Since the creation of the LSA category in 2004, 20 new U.S. manufacturers of LSA aircraft have emerged (Johnson, n.d.). The pilot population has increased by 4,066 pilots since 2004, when the new LSA rules were implemented. This figure represents an important contribution to an industry in which the total active pilot population has been dwindling over the last decade (GAMA, 2012). Part 23 has also been the entry point for many new aircraft technologies, including composite materials, satellite navigation and approaches, integrated glass cockpits, synthetic vision, and
Automatic Dependent Surveillance-Broadcast (ADS-B), among others (Bowles, 2010).

The Experimental-Amateur Built (E-AB) category constitutes the fastest-growing segment of the GA fleet in the U.S. (U.S. Government Accountability Office [GAO], 2012). One of the main advantages for people to acquire an $\mathrm{E}-\mathrm{AB}$, or convert a certified aircraft to the experimental category, is that one can make modifications to an aircraft without any coordination with the manufacturer (McClellan, 2013). E-AB aircraft are defined by the FAA as aircraft in which at least $51 \%$ of the aircraft was fabricated and assembled by an individual or a group of individuals and undertook the construction project solely for their own education or recreation.

In 2011, there were approximately 33,000 E-AB aircraft registered, a $10 \%$ increase from 2008, making E-AB aircraft the fastest-growing segment of the GA fleet (National Transportation Safety Board [NTSB], 2012a). On the other hand, the number of accidents involving E-AB aircraft had increased between 1999 and 2011; E-AB aircraft accounted for $14 \%$ of airplanes in nonfatal GA accidents and approximately $21 \%$ of fatal accidents. In 2012, the NTSB completed a safety study of E-AB aircraft. Among other findings, the NTSB concluded that the first 50 hours of flight, known as the flight test period for E-AB airplanes, are uniquely challenging for most pilots (NTSB, 2012b).

According to the NTSB study, power plant failures and loss of control in flight are the most common E-AB aircraft accident occurrences, and structural failures have not been a common occurrence among E-AB aircraft. In comparison with similar non-E-AB aircraft, a much higher proportion of accidents involving $\mathrm{E}-\mathrm{AB}$ aircraft occur early in the operational life of the aircraft or shortly after being purchased by a subsequent owner. The study also indicates that the majority of $\mathrm{E}-\mathrm{AB}$ aircraft are now built from commercial kits, rather than from purchased plans or

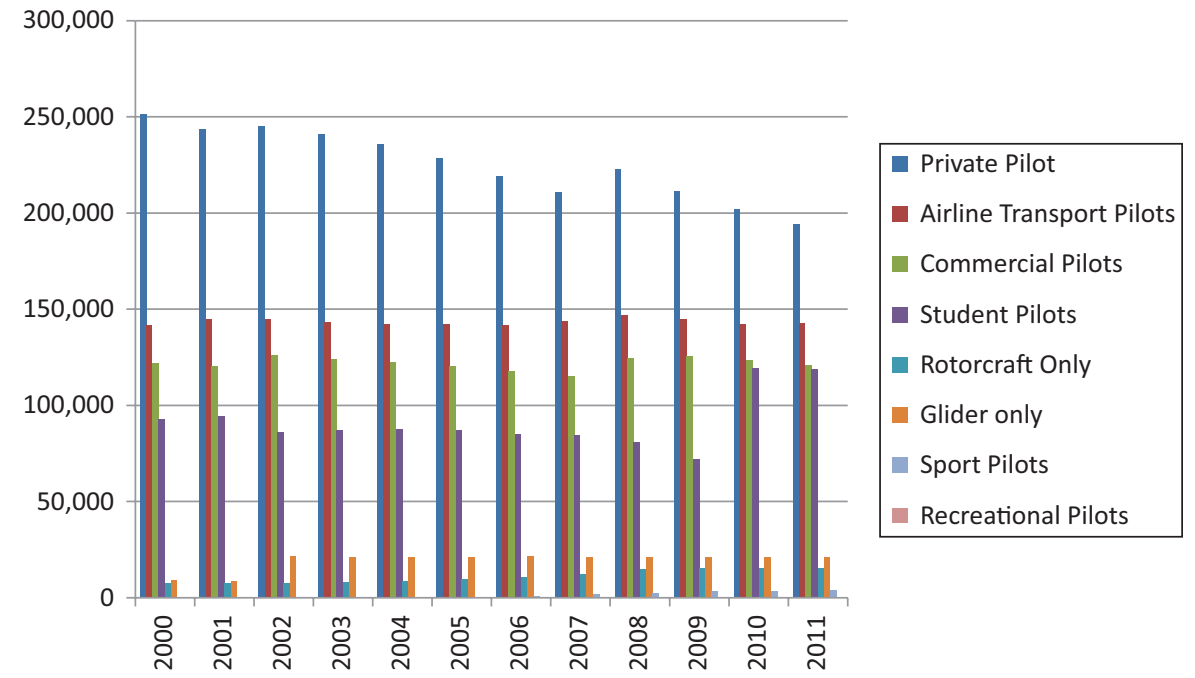

Figure 4. U.S. pilot population. Adapted from General Aviation Statistical Databook and Industry Outlook by GAMA (2012). 
original designs (NTSB, 2012b). According to the study, the pilots of E-AB aircraft have similar, or higher, levels of total aviation experience than pilots of non-E-AB aircraft engaged in similar GA operations; however, pilots of $\mathrm{E}-\mathrm{AB}$ accident aircraft, on average, had considerably less flight experience in the type of E-AB aircraft. FAR 91.319 (a)(2) prohibits the use of $\mathrm{E}-\mathrm{AB}$ airplanes for hire, including flight instruction and rental; therefore, finding suitable $\mathrm{E}-\mathrm{AB}$ aircraft and instructors available for training is difficult and presents a barrier to pilots seeking transition training (NTSB, 2012b).

The NTSB study also concluded that E-AB aircraft safety is largely managed by the community of E-AB aircraft builders, owners, and kit manufacturers rather than by FAA regulatory requirements; however, the FAA regulations mostly seek to ensure that the majority of work within the $\mathrm{E}-\mathrm{AB}$ aircraft building process is done by the builder (NTSB, 2012b). Airworthiness certificates are granted to the E-AB aircraft builder by the FAA based only on a review of documentation and a one-time inspection of the aircraft after it has been completed. Unlike other foreign civil aviation authorities' requirements, the FAA has no requirement for preapproval of the project or in-process inspections of materials and workmanship. According to the NTSB (2012b), a large proportion of E-AB aircraft accidents involving loss of engine power could be reduced by requiring documentation of a functional test of the aircraft fuel system as part of the initial airworthiness certification.

\section{Main Causes of GA Accidents}

According to the NTSB (2012a), in 2010, GA accidents accounted for $96 \%$ of all aviation accidents, $97 \%$ of fatal aviation accidents, and $96 \%$ of all fatalities for U.S. civil aviation. In addition, GA accounted for $51 \%$ of the estimated total flight time of all U.S. civil aviation in 2010. Figure 5 shows the total and fatal accidents for GA for the years from 2001 through 2010, including the experimental category. These accidents do not include commercial aviation operations, including Parts 121, 135, or 129 operations. These figures also do not include air medical, sightseeing, or air tour operations, since these types of accidents were discussed separately in the NTSB report (2012a).

The NTSB (2012a) report indicates that the number of GA accidents declined over the period of 2001 to 2010; however, the number of fatal accidents has remained steady over the same period of time. Fatal accidents account for approximately $19 \%$ of total accidents in GA; this percentage has also remained relatively steady, ranging from $17 \%$ to $20 \%$ between 2001 and 2010 (see Figure 5). The accident rate for both fatal and nonfatal accidents also remained relatively steady, as the number of hours flown have decreased during the same period of time. Figure 6 shows the estimated total flight hours for GA based on the GA Survey, and Figure 7 shows the accident rate for GA. One of the major limitations with GA activity data is that the number of hours flown per year and other activity information is obtained from the GA survey. The GA survey collects voluntary information from aircraft owners and operators (GAO, 2012). In order to maintain a more accurate count of the number of active aircraft, the FAA began requiring owners and operators of aircraft to renew aircraft registrations every three years, beginning in 2010 .

GA encompasses a wide range of operations and aircraft, from powered parachutes, gliders, and light sport aircraft to turboprops and jets used for a variety of missions. The majority of GA accidents in 2010 involved personal flying in fixed-wing airplanes, which accounted for 64\% (912) of the total number of accidents; the second category of GA accidents was flight instruction in fixed-wing airplanes, which accounted for 10\% (140) of the accidents (NTSB, 2012a).

In Stephens (2012), the FAA identified the top ten leading causes of fatal GA accidents to be (see Figure 8):

1. Loss of control in flight;

2. Controlled flight into terrain;

3. System or component failure/power plant;

4. Low altitude operations;

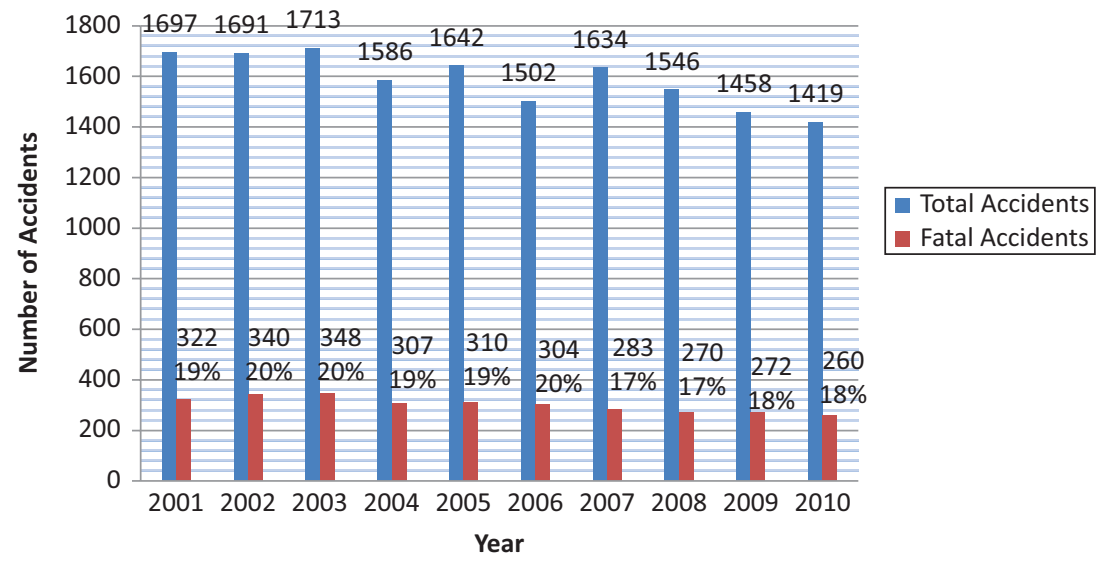

Figure 5. Total and fatal GA accidents. Adapted from Review of Aircraft Accident Data 2010 (NTSB, 2012a, p. 33). 


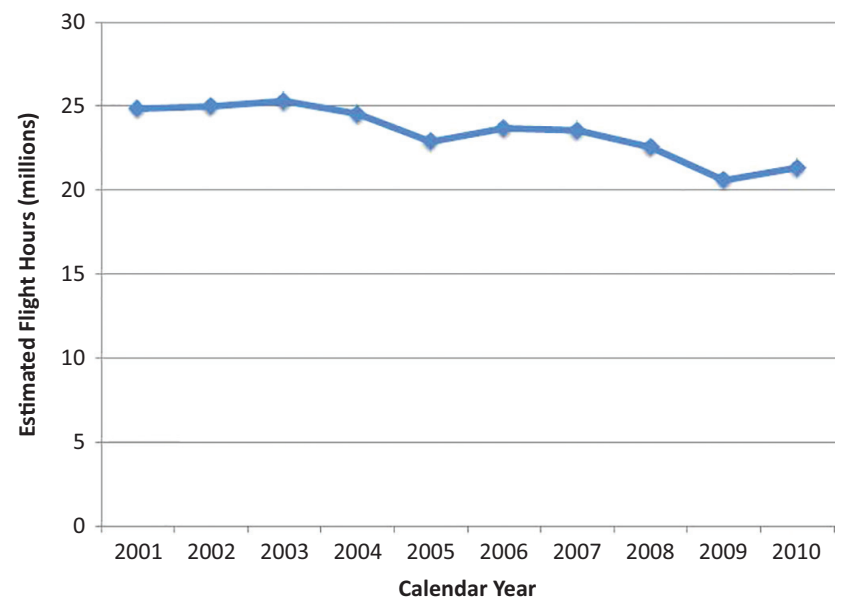

Figure 6. Estimated GA flight hours. Adapted from Review of Aircraft Accident Data 2010 (NTSB, 2012a, p. 35).

5. Unknown or undetermined;

6. Other;

7. Fuel related;

8. System component failure-non-power plant:

9. Midair collisions; and

10. Wind shear or thunderstorm.

According to the FAA (2011a), from 2010 to 2012, fatal accidents from CFIT have been reduced by more than $50 \%$ compared to the previous three years. Fatal accidents involving LOC in flight, during approach, and during landing have decreased by approximately $20 \%$ to $25 \%$. Meanwhile, fatal accidents caused by bad weather have decreased by nearly $40 \%$ in the past three years, and fatal accidents occurring at night decreased by about $25 \%$. The FAA attributes these reductions in fatal accidents to the use of technology such as Global Positioning System (GPS) with moving maps and in-flight weather capabilities. New technologies such as inflatable restraints, ballistic parachutes, data-link weather in the cockpit, Angle of Attack (AOA) indicators, traffic alert systems, and terrain

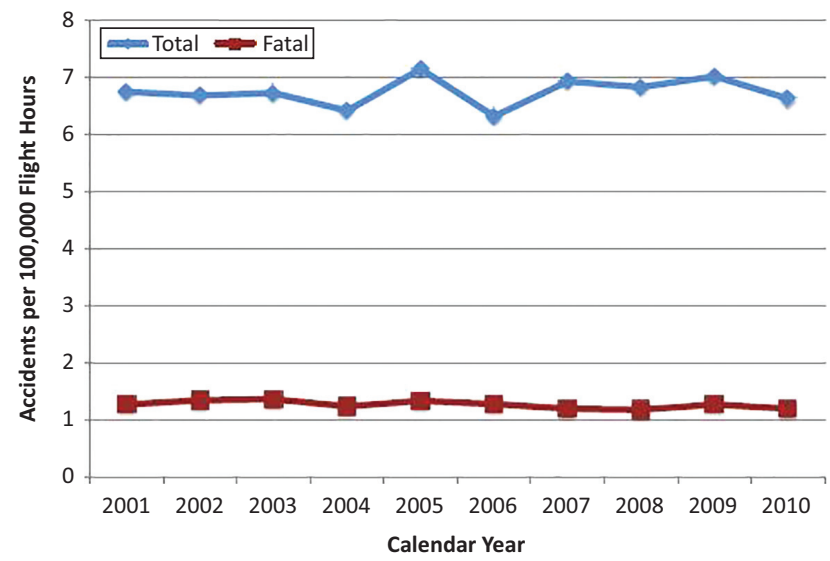

Figure 7. Total and fatal accident rates for GA. Adapted from Review of Aircraft Accident Data 2010 by (NTSB, 2012a, p. 36). avoidance equipment could continue reducing GA fatalities if these technologies are allowed to be implemented in certified airplanes. The FAA is making an effort to facilitate the approval process of AOA indicators and seatbelts with airbags in order to allow all GA aircraft to be eligible for the installation of these devices (FAA, 2011a).

In a further effort to reduce GA accidents, the General Aviation Joint Steering Committee (GAJSC) was formed in the mid-1990s and is currently renewing its accident reduction efforts. The GAJSC is a government and industry group that uses a data-driven, consensus-based approach to analyze safety data to develop specific interventions that will mitigate the root causes of accidents. The group released recommendations to address LOC during approach and landing (GAJSC, 2012). The report addresses the current Part 23 certification problems and emphasizes the importance of incorporating new technologies to prevent accidents. CFIT fatal accidents dropped 60\% between 2001 and 2010; the GAJSC (2012) attributes that improvement to the use of electronic information such as GPS position on a moving map, real-time weather, terrain awareness, and traffic awareness. These electronic devices have made a considerable contribution in the reduction of pilot workload. The GAJSC (2012) also emphasizes that most of the safety-enhancing technology that lowered the CFIT accident rate was in the form of handheld equipment not installed in the airplane, such as handheld GPS systems and tablets.

The GAJSC (2012) also recommended the use of AOA indicators and autopilots to prevent LOC accidents; however, these technologies, for the most part, must be installed in the airplane and are not available in the form of handheld equipment. The high cost of certification and installation keeps these technologies out of small certified airplanes. The report also states that the cost of installing an existing AOA system on a certified airplane is almost ten times higher than installing the same system on an experimental airplane.

According to the GAJSC (2012), LOC accidents at night and in Instrument Meteorological Conditions (IMC) would drop by $50 \%$ simply by installing autopilots in the more than 100,000 Instrument Flight Rules (IFR) capable GA airplanes. Autopilots can be installed in experimental airplanes for as low as $\$ 2,500$; however, installing an autopilot on a certified airplane could cost at least $\$ 10,000$, which represents between $10 \%$ and $50 \%$ of the average value of a GA airplane. The GAJSC (2012) report also recommended that the FAA apply a risk management approach to analyze whether the current certification regulations are actually an obstacle to installing safetyenhancing technology into the GA fleet.

Revitalizing the entry-level airplane market could have a beneficial effect on attracting new pilots, invigorating the manufacturing industry, and facilitating the retrofit of an aging fleet of over 200,000 airplanes. The use of international 


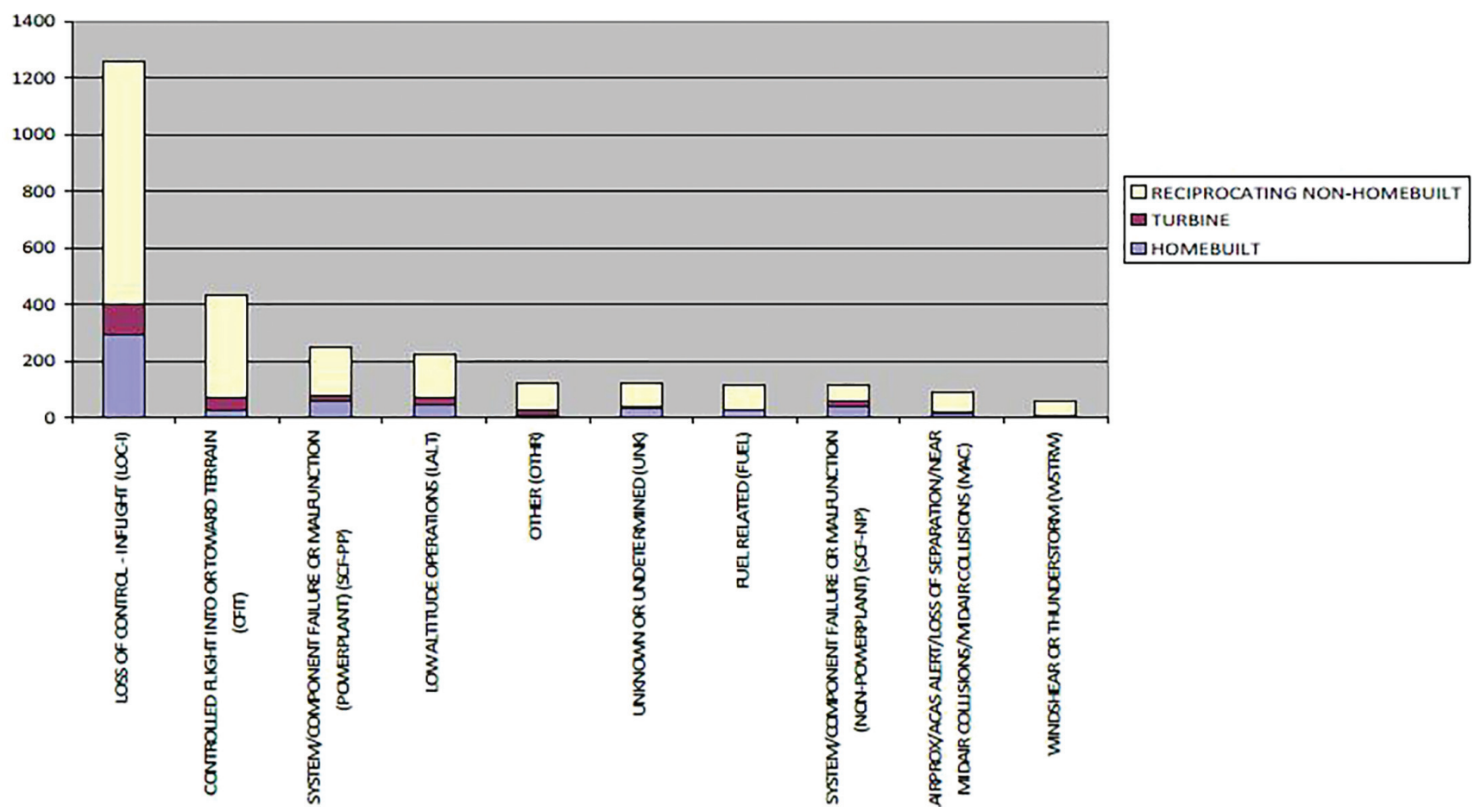

Figure 8. Top ten causes of GA fatal accidents. Adapted from Evolving GA to a Data-Driven and Proactive Process (Stephens, 2012).

industry consensus standards for aircraft certification may be an appealing alternative for the U.S. to maintain the competitive edge in a globalized marketplace.

\section{Methodology}

The study focused on analyzing GA accidents involving fixed-wing, single-engine, reciprocating-piston for the following reasons: (a) piston airplanes account for $67 \%$ of the total civil aircraft population, (b) the number of piston airplanes manufactured annually has been decreasing substantially over the last ten years, (c) $64 \%$ of GA accidents involved personal flying in fixed-wing airplanes, (d) $78 \%$ of personal flying was conducted in fixed-wing, single-engine piston airplanes, and (e) entry-level airplanes have been identified by the FAA as being the most affected by the increased difficulty and cost of certification.

The research concentrated on comparing airplane accidents based on airworthiness certification. The airworthiness categories utilized in the study were Part 23, CAR 3, S-LSA, ELSA, and E-AB. The time period selected for the accident occurrences was between January 1, 2004 and December 31, 2011 so as to include the LSA category that was created in 2004. The accident causes considered were:

- $\mathrm{LOC}$

- CFIT

- Engine Failure

- Structural Failure

\section{Research Approach}

The study employed a mixed-methods analysis that used an explanatory sequential design consisting of two phases (Teddie \& Tashakkori, 2009). The first phase was composed of the collection and analysis of quantitative data to address the study's hypotheses. The second phase consisted of the analysis of the qualitative data from the narrative section of the accident investigation reports utilizing text mining techniques.

\section{Design and Procedures}

The primary purpose of aircraft certification is to maximize safety by minimizing the number of accidents. Accidents involving the top three causes of accidents in GA (LOC, CFIT, and Engine Failure) were analyzed and compared based on aircraft airworthiness certification basis. In addition, accidents due to Structural Failure were also analyzed, as this is one of the failures or malfunctions that aircraft certification is designed to prevent.

The research focused on the overarching hypothesis that there is no significant difference in the frequency of accidents or in the accident rate among airplanes certified under Part 23, CAR 3, S-LSA, ELSA, or E-AB categories in which LOC, CFIT, Engine Failure, or Structural Failure was listed as a cause in the period between January 1, 2004 and December 31, 2011.

The quantitative portion of the study consisted of two parts. In the first part, a Chi-Square statistical test was conducted to compare the frequencies of accidents among airplanes certified under Part 23, CAR 3, S-LSA/E-LSA, or 
E-AB in which LOC, CFIT, Engine Failure, or Structural Failure was listed as a cause from 2004 to 2011. If the ChiSquare test value had a probability of less than $.05(p<.05)$, the null hypothesis would be rejected. In the second part, an ANCOVA statistical test was utilized to compare the accident rates among airplanes certified under Part 23/CAR 3, SLSA/ELSA, or E-AB in which LOC, CFIT, Engine Failure, or Structural Failure was listed as a cause from 2004 to 2011. If the $F$-statistic in the ANCOVA test had a probability of less than $.05(p<.05)$, then the null hypothesis would be rejected.

For the ANCOVA statistical test, the dependent variable used was accident rate. The accident rate was calculated by dividing the number of accidents per year for each of the aircraft airworthiness categories by the number of hours flown per year for each category; these data were obtained from the GA activity survey, shown in Table 3 (GAMA, 2012). The fixed factor or independent variable used was airworthiness certification basis. In order to account for pilot experience, design stage of the airplane, and age of the airplane, the number of hours on the airplane's airframe and the number of hours of total flight time of the pilot were used as covariates. Covariates are not part of the dependent or independent variables, but have the potential to have an influence on the dependent variable (Field, 2009).

Following the quantitative analysis, the qualitative portion of the study consisted of the analysis of the narrative cause section of the NTSB reports for accidents in which LOC was listed as a cause. LOC accidents are of special interest because they are the main cause of GA accidents (Stephens, 2012). LOC is of particular interest to the FAA as it relates to aircraft certification because the GAJSC (2012) recommended the use of AOA indicators and autopilots to prevent LOC accidents; however, these technologies, for the most part, must be installed in the airplane and are not available in the form of handheld equipment. The high cost of certification and installation deters airplane owners and operators from incorporating these technologies in small GA airplanes. The GAJSC (2012) also stated that the cost of installing an existing AOA system on a certified airplane is almost ten times higher than installing the same system on an experimental airplane.

Text mining techniques were used to analyze the qualitative portion of the NTSB accident reports, more specifically the narrative cause section. These narratives consisted of a few sentences or a few paragraphs of text, depending on the complexity and nature of the accident. The information in the narrative cause section can vary within the database as (a) different reporters may include various levels of detail, and (b) different causes and factors leading to the accident are confined within the narrative. Text mining can help identify sets of related words from the narrative cause portion of the report; it can also identify clusters of similar circumstances, possible patterns, and relationships among accidents (Nisbet, Elder, \& Miner, 2009).

\section{Population and Sample}

The population for the study consisted of all U.S. fixed-wing, single-engine, reciprocating-piston airplanes with maximum certificated takeoff weights of less than 12,500 pounds. The sample consisted of accidents of single-engine piston, fixedwing airplanes with maximum certified takeoff weights of less than 12,500 pounds between January 1, 2004 and December 31, 2011. The airworthiness certification categories used for the study were: (a) standard category, which also includes normal, utility, and aerobatic; (b) LSA; and (c) amateur-built airplanes within the experimental category. The airworthiness categories excluded from the sample were limited, restricted, special flight, provisional, transport, and unknown. The start of the time period selected was based on the creation of the LSA category in 2004; the end of the time period selected was based on the availability of NTSB accident reports with a probable cause.

\section{Sources of the Data}

The sources of data to obtain the airplane accident information were: (a) a public accessible NTSB accident database available online in Microsoft Access ${ }^{\circledR}$ format, and (b) the FAA type certificate database. The FAA type certificate database was used to determine the aircraft certification basis.

\section{Hypothesis Testing}

The purpose of this study was to analyze the frequency of GA airplane accidents and accident rates on the basis of aircraft certification to determine whether or not differences in aircraft certification rules had an influence on accidents. The certification categories examined were: Part 23, CAR 3, LSA, and $\mathrm{E}-\mathrm{AB}$. The accident causes examined were those listed as: LOC, CFIT, Engine Failure, and Structural Failure in the time period between January 1, 2004, and December 31, 2011.

The hypotheses were:

$H_{0} 1$. There is no significant difference in the frequency of accidents among airplanes certified in the Part 23, CAR 3, S-LSA/E-LSA, or E-AB categories with regard to accidents in which LOC was listed as a cause from 2004 to 2011.

If the Chi-Square test value had a probability of less than $.05(p<.05)$, then the null hypothesis would be rejected.

$\boldsymbol{H}_{\boldsymbol{0}}$ 2. There is no significant difference in the frequency of accidents among airplanes certified in the Part 23, CAR 3, S-LSA/E-LSA, or E-AB categories with regard to accidents in which CFIT was listed as a cause from 2004 to 2011.

If the Chi-Square test value had a probability of less than $.05(p<.05)$, then the null hypothesis would be rejected. 
$\boldsymbol{H}_{\boldsymbol{0}} 3$. There is no significant difference in the frequency of accidents among airplanes certified in the Part 23, CAR 3, S-LSA/E-LSA, or E-AB categories with regard to accidents in which Engine Failure was listed as a cause from 2004 to 2011.

If the Chi-Square test value had a probability of less than $.05(p<.05)$, then the null hypothesis would be rejected.

$\boldsymbol{H}_{0} 4$. There is no significant difference in the frequency of accidents among airplanes certified in the Part 23, CAR 3, S-LSA/E-LSA, or E-AB categories with regard to accidents in which Structural Failure was listed as a cause from 2004 to 2011.

If the Chi-Square test value had a probability of less than $.05(p<.05)$, then the null hypothesis would be rejected.

$\boldsymbol{H}_{\mathbf{0}}$ 5. There is no significant difference in the accident rate among airplanes certified in the Part 23/CAR 3, S-LSA/E-LSA, or E-AB categories with regard to accidents in which LOC was listed as a cause from 2004 to 2011 .

If the $F$-statistic in the ANCOVA test has a probability of less than $.05(p<.05)$, then the null hypothesis would be rejected.

$\boldsymbol{H}_{0}$ 6. There is no significant difference in the accident rate among airplanes certified in the Part 23/CAR 3, SLSA/E-LSA, or E-AB categories with regard to accidents in which CFIT was listed as a cause from 2004 to 2011.

If the $F$-statistic in the ANCOVA test has a probability of less than $.05(p<.05)$, then the null hypothesis would be rejected.

$\boldsymbol{H}_{\boldsymbol{0}}$ 7. There is no significant difference in the accident rate among airplanes certified in the Part 23/CAR 3, SLSA/E-LSA, or E-AB categories with regard to accidents in which Engine Failure was listed as a cause from 2004 to 2011.

If the $F$-statistic in the ANCOVA test has a probability of less than $.05(p<.05)$, then the null hypothesis would be rejected.

$\boldsymbol{H}_{\boldsymbol{0}}$ 8. There is no significant difference in the accident rate among airplanes certified in the Part 23/CAR 3, S-LSA/E-LSA, or E-AB categories with regard to accidents in which Structural Failure was listed as a cause from 2004 to 2011.

If the $F$-statistic in the ANCOVA test has a probability of less than $.05(p<.05)$, then the null hypothesis would be rejected.

\section{Qualitative Data}

The qualitative data for the study was extracted from the narrative cause section of the NTSB accident investigation reports. The qualitative results helped explain the initial quantitative results (Teddie \& Tashakkori, 2009). Text mining techniques were utilized to help analyze the qualitative portion of the NTSB accident reports.

The text mining function of the STATISTICA Data Mining Software was utilized to analyze the dataset. This text mining function aids in the identification of the main words encountered in the document, along with their frequency. A variety of plots are available, including a scree plot and a scatter plot. The scree plot indicates the different dimensions and the percentage of the total variance. The elbow or point of inflection of the scree plot indicates the words that appear most frequently. The scatter plot allows for the identification of word groups or clusters.

\section{Results}

Table 1 shows the frequency of accidents by cause and certification basis for all accidents that met the criteria of the study.

\section{Descriptive Statistics}

The descriptive statistics are shown in Table 2. Some information, such as the number of hours on the airframe, was missing for many NTSB accident reports; however, this variable was not one of the critical variables utilized in the study. Therefore, the average of the hours on the airframe per year was calculated with the available data and utilized as a covariate.

Table 3 provides information about the number of hours on the airframe and the pilot total flight time by certification category. S-LSA, E-LSA, and E-AB airplanes are, on average, newer than Part 23 and CAR 3 airplanes. The average pilot flight times did not differ substantially. As expected, the CAR 3 airplanes' average number of hours on the airframe was higher than the other categories because they are the oldest airplanes.

Table 4 provides the frequency and type of pilot certificate, as well as whether or not there was an instructor on board. As Table 4 shows, $54 \%$ of the pilots in the sample

Table 1

Frequency of Accidents by Cause and Certification Basis for all Accidents from 2004-2011

\begin{tabular}{lrrrrrr}
\hline $\begin{array}{l}\text { Cause/Cert. } \\
\text { Basis }\end{array}$ & CAR 3 & Part 23 & E-AB & S-LSA & E-LSA & Total/Cause \\
\hline LOC & 618 & 196 & 266 & 41 & 34 & 1,155 \\
CFIT & 405 & 76 & 75 & 6 & 1 & 563 \\
Eng. Fail. & 587 & 127 & 216 & 15 & 28 & 973 \\
Str.Fail. & 176 & 51 & 91 & 11 & 3 & 332 \\
Total & $\mathbf{1 , 7 8 6}$ & $\mathbf{4 5 0}$ & $\mathbf{6 4 8}$ & $\mathbf{7 3}$ & $\mathbf{6 6}$ & $\mathbf{3 , 0 2 3}$ \\
Other & 2,258 & 588 & 467 & 78 & 41 & 3,432 \\
Total/ Cert. & $\mathbf{4 , 0 4 4}$ & $\mathbf{1 , 0 3 8}$ & $\mathbf{1 , 1 1 5}$ & $\mathbf{1 5 1}$ & $\mathbf{1 0 7}$ & $\mathbf{6 , 4 5 5}$ \\
$\quad$ & & & & & \\
$\quad$ Basis & & & & & & \\
\end{tabular}


Table 2

Descriptive Statistics

\begin{tabular}{lcccc}
\hline & Certificated Weight & Airframe Hours & Pilot Hours & No. of Seats \\
\hline Valid & 3,023 & 2,571 & 2,951 & 72 \\
Missing & 0 & 452 & $2,929.62$ & 29 \\
Mean & $2,271.98$ & $3,260.46$ & 961.00 & 3.23 \\
Median & $2,300.00$ & $2,740.00$ & 1,000 & 4.00 \\
Mode & 2,300 & 0 & $5,336.42$ & 4 \\
SD & 935.45 & $3,572.64$ & 3.53 & 1.40 \\
Skewness & 1.05 & 6.72 & 0 & .51 \\
Kurtosis & 6.23 & 133.42 & 0 & 1 \\
Min & 388 & 0 & 334.00 & 29 \\
25 Percentile & $1,600.00$ & 601.00 & 961.00 & 2.00 \\
50 Percentile & $2,300.00$ & $2,740.00$ & 2800.00 & 4.00 \\
75 Percentile & $2,900.00$ & $4,598.00$ & 55,000 & 4.00 \\
Max. & 12,000 & 89,118 & & 11 \\
\hline
\end{tabular}

had at least a private pilot certificate, $26 \%$ had a commercial certificate, and $10 \%$ had an ATP. Only $0.2 \%$, or 5 accidents, had unknown or missing information about the pilot certificate. An instructor was on board in $22 \%$ of the sample accidents.

The frequency of accidents by cause is displayed in Figure 9. Airplanes certified under CAR 3 rules account for $53.5 \%$, or 618 , of the accidents in which LOC was listed as a cause between the period of January 1, 2004 and December 31, 2011. Airplanes certified under CAR 3 rules also account for $62.65 \%$ of the total accidents within the same period.

The general trend of the rate of accidents by certification basis for Part 23/CAR 3 certified airplanes has remained nearly constant, as shown in Figure 10. The large spike in the accident rate for LSA can be attributed to the start of the category in 2004; production of LSA airplanes began in 2005 with only three accidents and 9,000 hours flown that year in the LSA category.

Table 5 shows the frequency of accidents, number of active aircraft, hours flown, and accident rate by certification basis. Figure 11 shows the accident rate by accident cause and certification basis. The accident rate for the LSA and E-AB categories for accidents in which LOC was listed as a cause is higher than for Part 23 category airplanes, even though Part

Table 3

Descriptive Statistics for Airframe Hours and Pilot Hours by Aircraft Certification Categories

\begin{tabular}{llrrrrr}
\hline Cert. Basis & Covariate & Valid & Min & Max & Mean & SD \\
\hline CAR 3 & Airframe Hours & 1,541 & 25 & 89,118 & $3,884.00$ & $3,758.65$ \\
& Pilot Hours & 1,749 & 0 & 55,000 & $3,041.09$ & $5,601.17$ \\
PART 23 & Airframe Hours & 408 & 3 & 12,616 & $2,272.62$ & $2,089.72$ \\
& Pilot Hours & 445 & 0 & 49,800 & $2,535.31$ & $4,624.89$ \\
E-AB & Airframe Hours & 509 & 0 & 19,611 & 412.31 & $1,066.85$ \\
& Pilot Hours & 624 & 0 & 33,000 & $2,840.22$ & $4,853.78$ \\
E-LSA & Airframe Hours & 48 & 0 & 12,691 & 495.08 & $1,808.81$ \\
& Pilot Hours & 61 & 10 & 31,270 & $3,857.84$ & $7,465.82$ \\
S-LSA & Airframe Hours & 64 & 0 & 3,542 & 312.28 & 533.57 \\
& Pilot Hours & 71 & 8 & 25,000 & $2,652.01$ & $4,621.59$ \\
\hline
\end{tabular}

23 airplanes account for 814 accidents in which LOC was listed as a cause and LSA airplanes were only involved in 75 accidents in which LOC was listed as a cause between the years of 2004 and 2011. The higher accident rate for LSA airplanes is attributed to the much lower number of estimated hours flown during the same period. The accident rates for Part 23 and LSA airplanes in which CFIT was listed as a cause are nearly equal.

\section{Discussion, Conclusions, and Recommendations}

\section{Discussion}

A total of 6,455 accidents met the initial airworthiness certification criteria of this study. The total number of accidents involving LOC, CFIT, Engine Failure, or Structural Failure was 3,023 (see Table 4). These accidents were utilized for the analyses to address the hypotheses. The sample consisted of: 1,155 LOC accidents, 563 CFIT accidents, 973 Engine Failure accidents, and 332 Structural Failure accidents. The number of accidents by certification category were: 1,786 accidents for CAR 3, 450 accidents for

Table 4

Frequency of Pilot Certificate Type and Instructor On-board

\begin{tabular}{lcc}
\hline Pilot Certificate Type & Frequency & Percent \\
\hline Private & 1,639 & 54.2 \\
Commercial & 787 & 26 \\
ATP & 349 & 10.8 \\
Student & 137 & 4.5 \\
None & 59 & 2.0 \\
Sport & 44 & 1.5 \\
Unknown & 5 & .2 \\
Recreational & 2 & .1 \\
Foreign & 1 & .0 \\
Total & $\mathbf{3 , 0 2 3}$ & $\mathbf{1 0 0 . 0}$ \\
\hline Instructor on-board & Frequency & Percent \\
\hline No & 2,359 & 78 \\
Yes & 664 & 22 \\
\hline
\end{tabular}




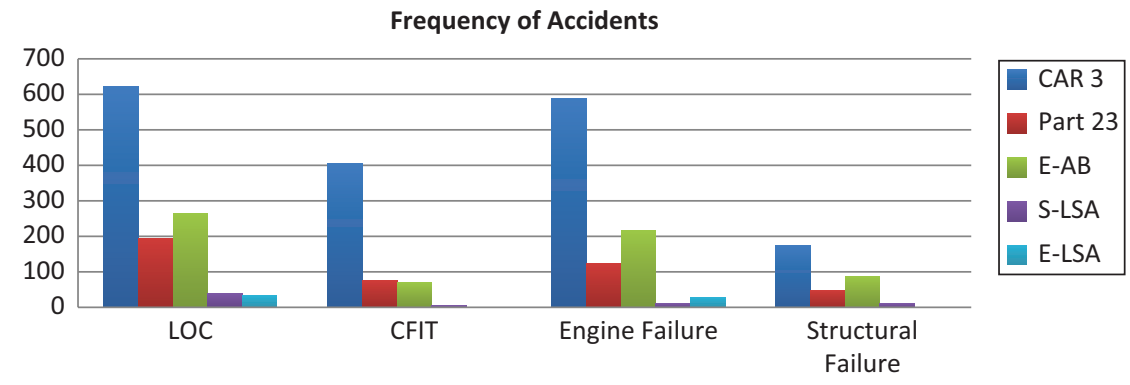

Figure 9. Frequency of accidents by cause and certification basis.

Part 23, 648 accidents for E-AB, 73 accidents for S-LSA, and 66 accidents for E-LSA.

\section{Hypothesis Testing}

The evaluation of eight hypotheses under investigation was conducted utilizing two main statistical methods: ChiSquare test and ANCOVA. Discussion of the statistical significance of the hypotheses follows.

To address hypotheses one through four, Chi-Square tests were performed to determine whether the different causes of accidents were distributed differently across certification basis categories; therefore, the null hypotheses were: there is no significant difference in the frequency of accidents among airplanes certified under Part 23, CAR 3, SLSA/ELSA or E-AB in which LOC, CFIT, Engine Failure, or Structural Failure was listed as a cause between the years of 2004 and 2011. Since only the accident frequencies were utilized for the Chi-Square test, the amount of activity, or the number of active airplanes for each category, was not taken into account. The Chi-Square test compares the observed and expected frequencies; the test determines if the expected values differ significantly from the observed values. The standardized residuals show the difference between the expected frequencies and the observed frequencies. The individual standardized residuals provide very useful information about the contribution of each of the

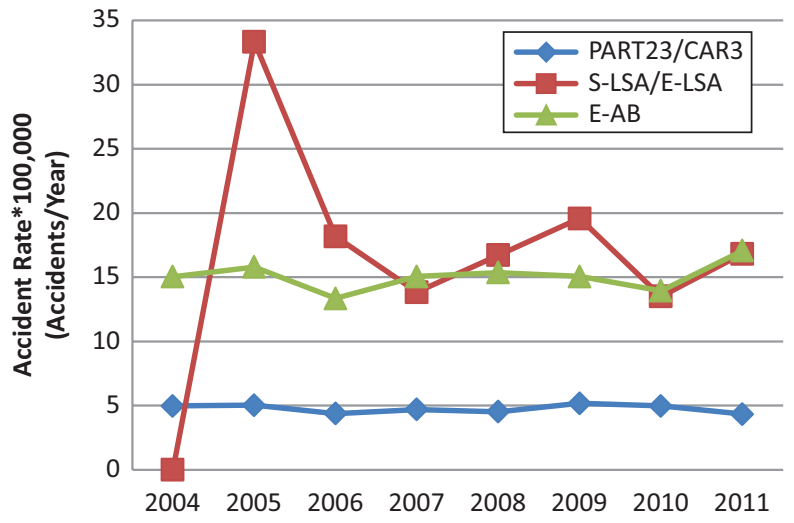

Figure 10. Accident rate by year and certification basis for study sample. Note: The accident rate is given in number of accidents per year per 100,000 hours. expected and observed frequencies to the overall association that the Chi-Square statistic measures (Field, 2009).

$\boldsymbol{H}_{0}$ 1. The null hypothesis tested was that there is no significant difference in the frequency of accidents among airplanes certified under Part 23, CAR 3, SLSA/E-LSA, or E-AB categories with regard to accidents in which LOC was listed as a cause. The ChiSquare test indicated that there was a significant difference in the frequency of accidents in which LOC was listed as a cause. The post-hoc analysis indicated that the significant difference was among Part 23, CAR 3, and $\mathrm{E}-\mathrm{AB}$ categories; however, it indicated no significant difference in the frequency of accidents among the SLSA/ELSA category for LOC accidents (see Appendix Table C.1). The standardized residuals also indicated that the CAR 3 and S-LSA/E-LSA categories had significant difference in frequencies; the Part 23 and E-AB categories did not have any significant residuals.

$\boldsymbol{H}_{0} 2$. The null hypothesis tested was that there is no significant difference in the frequency of accidents among airplanes certified in the Part 23, CAR 3, SLSA/E-LSA, or E-AB categories with regard to accidents in which CFIT was listed as a cause. The ChiSquare test indicated that there was no significant difference in the frequency of accidents in which CFIT was listed as a cause.

$\boldsymbol{H}_{0} 3$. The null hypothesis tested was that there is no significant difference in the frequency of accidents among airplanes certified in the Part 23, CAR 3, SLSA/E-LSA, or E-AB categories with regard to accidents in which Engine Failure was listed as a cause. The Chi-Square test indicated that there was a significant difference in the frequency of accidents in which Engine Failure was listed as a cause.

$\boldsymbol{H}_{0} 4$. The null hypothesis tested was that there is no significant difference in the frequency of accidents among airplanes certified in the Part 23, CAR 3, SLSA/E-LSA, or E-AB categories with regard to accidents in which Structural Failure was listed as a cause. The Chi-Square test indicated that there was no significant difference in the frequency of accidents in which Structural Failure was listed as a cause. 
Table 5

Frequency of Accidents, Active Airplanes, Hours Flown, and Accident Rate by Cause and Certification Basis for 2004-2011

\begin{tabular}{|c|c|c|c|c|c|}
\hline Accident Cause & Cert. Basis & No. accidents & Hours Flown & No. Active Airplanes & Accident Rate \\
\hline \multirow[t]{3}{*}{ LOC } & PART 23/CAR 3 & 814 & $106,850,031$ & 149,711 & $7.62 \mathrm{E}-06$ \\
\hline & LSA & 75 & $1,581,539$ & 4,545 & 4.74E-05 \\
\hline & E-AB & 266 & $7,392,719$ & 21,106 & $3.60 \mathrm{E}-05$ \\
\hline \multirow[t]{3}{*}{ CFIT } & PART 23/CAR 3 & 481 & $106,850,031$ & 149,711 & $4.50 \mathrm{E}-06$ \\
\hline & LSA & 7 & $1,581,539$ & 4,545 & 4.43E-06 \\
\hline & $\mathrm{E}-\mathrm{AB}$ & 75 & $7,392,719$ & 21,106 & $1.01 \mathrm{E}-05$ \\
\hline \multirow[t]{3}{*}{ Engine Failure } & PART 23/CAR 3 & 714 & $106,850,031$ & 149,711 & $6.68 \mathrm{E}-06$ \\
\hline & LSA & 43 & $1,581,539$ & 4,545 & $2.72 \mathrm{E}-05$ \\
\hline & $\mathrm{E}-\mathrm{AB}$ & 187 & $7,392,719$ & 21,106 & $2.53 \mathrm{E}-05$ \\
\hline \multirow[t]{3}{*}{ Structural Failure } & PART 23/CAR 3 & 227 & $106,850,031$ & 149,711 & $2.12 \mathrm{E}-06$ \\
\hline & LSA & 14 & $1,581,539$ & 4,545 & $8.85 \mathrm{E}-06$ \\
\hline & E-AB & 113 & $7,392,719$ & 21,106 & $1.53 \mathrm{E}-05$ \\
\hline
\end{tabular}

To address hypotheses five through eight, a series of one-way factorial ANCOVA tests with covariates (ANCOVAs) was performed to determine whether or not there is a significant difference in the accident rate among airplanes certified under Part 23/CAR 3, SLSA/ELSA, or E-AB in which LOC, CFIT, Engine Failure, or Structural Failure was listed as a cause after controlling for pilot flight time and number of hours on the aircraft's airframe. Therefore, the null hypotheses were: there is no significant difference in the accident rate among airplanes certified under Part 23/CAR 3, S-LSA/ELSA, or E-AB in which LOC, CFIT, Engine Failure, or Structural Failure was listed as a cause. The CAR 3 and Part 23 categories were combined into one group and the SLSA and ELSA categories were combined into another group for this analysis, as the total hours per year used to calculate the accident rate were only available for the combined categories.

$\boldsymbol{H}_{0}$ 5. The null hypothesis tested was that there is no significant difference in the accident rate among airplanes certified in the Part 23/CAR 3, S-LSA/ELSA, or $\mathrm{E}-\mathrm{AB}$, with regard to accidents in which $\mathrm{LOC}$ was listed as a cause. The ANCOVA test indicated that there was no significant difference in the accident rate among airplanes certified in the Part 23/CAR 3, SLSA/ELSA or
$\mathrm{E}-\mathrm{AB}$, with regard to accidents in which LOC was listed as a cause.

$\boldsymbol{H}_{\boldsymbol{0}}$ 6. The null hypothesis tested was that there is no significant difference in the accident rate among airplanes certified in the Part 23/CAR 3, SLSA/ELSA, or E-AB, with regard to accidents in which CFIT was listed as a cause. The ANCOVA test indicated that there was no significant difference in the accidents rate among airplanes certified in the Part 23/CAR 3, SLSA/ELSA, or E-AB, with regard to accidents in which CFIT was listed as a cause.

$\boldsymbol{H}_{0}$ 7. The null hypothesis tested was that there is no significant difference in the accident rate among airplanes certified in the Part 23/CAR 3, SLSA/ELSA, or E-AB, with regard to accidents in which Engine Failure was listed as a cause. The ANCOVA test indicated that there was a significant difference in the accident rate among airplanes certified in the Part 23/CAR 3, SLSA/ELSA, or E-AB, with regard to accidents in which Engine Failure was listed as a cause. There was also a significant interaction between the certification basis and the effects of the number of total flight time of the pilot; there was no significant interaction between certification basis and the number of hours on the airplane's airframe. The pair-wise

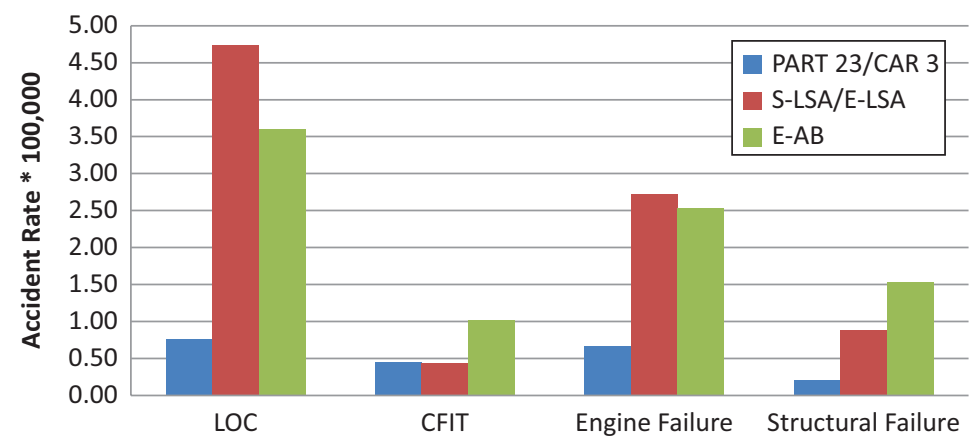

Figure 11. Accident rate by accident cause and certification basis.

Note: The accident rate is given in number of accidents per year per 100,000 hours. 
post-hoc analysis indicated that there were significant differences between E-AB and Part 23/CAR 3 airplanes, and between E-AB and SLSA/ELSA airplanes; however, there was not a significant difference between Part 23/CAR 3 and SLSA/ELSA airplanes with regards to the means of the accident rates in which Engine Failure was listed as a cause.

$\boldsymbol{H}_{\boldsymbol{0}}$ 8. The null hypothesis tested was that there is no significant difference in the accident rate among airplanes certified in the Part 23/CAR 3, SLSA/ELSA, or E-AB, with regard to accidents in which Structural Failure was listed as a cause. The ANCOVA test indicated that there was no significant difference in the accident rate among airplanes certified in the Part 23/CAR 3, SLSA/ELSA, or E-AB, with regard to accidents in which Structural Failure was listed as a cause.

\section{Text Mining}

Text mining was used to analyze the narrative causes of accident reports. Only the narrative causes of accidents in which LOC was listed as a cause were analyzed. The first analysis of accidents in which LOC was listed as a cause for all aircraft certification categories indicated three main groups of words or clusters. The first cluster was associated with LOC during takeoffs and landings, the second cluster was associated with maneuvering flight, and the third cluster was associated with low visibility, degraded weather conditions, and VFR flight into IMC. Accidents involving the Part 23 category had a cluster of words associated with spatial disorientation and instrument flight. The CAR 3 category had a cluster associated with low visibility, poor weather conditions, night, and VFR flight into IMC conditions. The E-AB and LSA airplanes did not have any clusters of words associated with low visibility, poor weather conditions, or VFR flight into IMC.

\section{Conclusions}

The results of the study indicated that GA aircraft certification rules do not have a statistically significant effect on the frequency of CFIT accidents or the accident rate. Based on the literature, CFIT fatal accidents dropped $60 \%$ between 2001 and 2010 (GAJSC, 2012). This decrease in the number of CFIT accidents is attributed largely to electronic devices, mainly in the form of handheld equipment, that have made a considerable contribution in the reduction of pilot workload (GAJSC, 2012).

The results of the study indicate that GA aircraft certification rules have a statistically significant effect on the frequency of LOC accidents, but not on the accident rate. LOC accounted for 1,155 accidents, an accident rate of 0.99 per 100,000 hours flown, or $18 \%$ of all the accidents between 2004 and 2011, and is the number one cause of accidents in GA. These results are consistent with previous studies and support the need to focus on LOC prevention for
GA to reduce the overall frequency of GA accidents and the accident rate (GAJSC, 2012; GAO, 2012; NTSB, 2012b). Airplanes certified under CAR 3 rules accounted for $53.5 \%$, or 618 of the accidents in which LOC was listed as a cause, and also accounted for $62.65 \%$ of the total accidents between 2004 and 2011.

The text mining analysis of the qualitative portion of the accident reports showed that CAR 3 airplanes, unlike the other categories, were involved in LOC accidents associated with low visibility, poor weather conditions, night, and VFR flight into IMC conditions. CAR 3 airplanes were designed and manufactured prior to the 1960s and are the oldest airplanes of the GA fleet. CAR 3 airplanes, in most cases, have not been retrofitted to take advantage of the newer technologies that could possibly aid in the prevention of LOC accidents. According to the literature, LOC accidents at night and in IMC would drop by $50 \%$ simply by installing autopilots in the more than 100,000 IFR-capable GA airplanes (GAJSC, 2012).

The results of the study indicate that GA aircraft certification rules have a statistically significant effect on the frequency of Engine Failure accidents and the accident rate. The results of the study also indicate that there was a significant difference in the accident rate of Engine Failure accidents between E-AB and Part 23/CAR 3, and between E-AB and S-LSA/E LSA airplanes; however, there was not a significant difference between airplanes certified under S-LSA/E-LSA or Part 23/CAR 3. As found in the literature, many of the Engine Failure accidents in the E-AB category occur during the first few hours of operation of a newly built aircraft or shortly after being purchased by a new owner; the majority of these accidents are due to design and installation problems with the engine and fuel systems (NTSB, 2012b). The majority of E-AB airplanes are built from commercially available kits rather than from plans or original designs (NTSB, 2012b). As explained in the literature, a primary focus of the FAA regulations that oversee the E-AB building process seeks to ensure that the majority of the construction of the airplane is performed by the builder (NTSB, 2012b). Airworthiness certificates are granted to the builder of an E-AB aircraft by the FAA based on the review of the paperwork and a one-time inspection of the airplane once the airplane has been completed (NTSB, 2012b). A functional test of the airplane's fuel system is required by civil aviation authorities in other countries, but it is not required by the FAA (NTSB, 2012b).

The results of this study indicate that the average pilot flight times did not differ substantially among the different certification categories; this result is supported by the literature. On the other hand, the literature also indicates that pilots of E-AB accident aircraft, on average, had considerably less flight experience in the make and model of E-AB airplanes (NTSB, 2012b). E-AB aircraft are not allowed to be operated for compensation or hire, which includes flight instruction; therefore, the difficulty of 
finding suitable E-AB aircraft and instructors available for training presents a barrier to pilots seeking transition training (NTSB, 2012b).

The results of the study indicated that GA aircraft certification rules do not have a statistically significant effect on the frequency of Structural Failure accidents or the accident rate. Structural Failure is one of the failures or malfunctions that aircraft certification is designed to prevent. Structural Failure is not one of the leading causes of accidents in GA, and based on the results of this study, Structural Failure accidents accounted for 332 accidents, an accident rate of 0.30 per 100,000 hours flown, or $5 \%$ of all the accidents between 2004 and 2011. Therefore, it appears that, regardless of the amount of government oversight with regards to certification, the FAA has been able to minimize the amount of accidents due to Structural Failure.

In summary, GA aircraft certification rules do not have a statistically significant effect on aircraft accidents except on the frequency of LOC accidents, and on the frequency and accident rate of Engine Failure accidents. With respect to LOC accidents, it appears that government oversight could have become an obstacle in the implementation and installation of new safety enhancing equipment into old aircraft that could possibly reduce the number of LOC accidents. With respect to Engine Failure accidents, aircraft certification oversight within the E-AB category is precluding $\mathrm{E}-\mathrm{AB}$ aircraft owners from being able to receive flight instruction and becoming proficient in specific E-AB models, and also from allowing professional organizations to complete and flight test their E-AB airplanes. On the other hand, government oversight should focus on ensuring that E-AB aircraft owners perform a functional test before obtaining an airworthiness certificate. A functional test could prevent some of the Engine Failure accidents that occur in the first few hours of operation of E-AB airplanes.

\section{Recommendations}

The results of this study indicate that there is a significant difference in the frequency of accidents and the accident rate among E-AB and the other two major categories: (a) Part23/CAR 3, and (b) SLSA/E-LSA for accidents in which Engine Failure was listed as a cause. Based on the literature and the results of this study, the FAA's oversight emphasis on E-AB aircraft should be shifted to allow E-AB aircraft to be completed and flight tested by professional organizations, thereby reducing some of the accidents due to installation and flight test errors. The FAA should also consider allowing transition flight training in E-AB aircraft, thereby increasing pilot proficiency in specific types of E$\mathrm{AB}$ airplanes. In addition, to reduce Engine Failure accidents in E-AB aircraft, the FAA should require a functional test of the airplane's systems, including the fuel system, before the airworthiness certificate is issued to the builder (NTSB, 2012b).
To reduce the accident rate and the frequency of LOC accidents in GA, it is important to focus on the airplanes certified under CAR 3 rules for three reasons: (a) CAR 3 airplanes consist of the oldest airplanes of the GA fleet; (b) CAR 3 airplanes were designed and manufactured prior to the 1960s, and in most cases, have not been retrofitted to take advantage of the newer technologies; and (c) the text mining analysis showed that CAR 3 airplanes were involved in LOC accidents associated with poor weather conditions and VFR flight into IMC conditions. The use of AOA indicators and autopilots to prevent LOC accidents should be assessed. The FAA should facilitate the retrofit of the legacy fleet with safety-enhancing technology, if this technology proves to be helpful in the prevention of LOC accidents.

As indicated by the text mining analysis of the narrative cause of the accident reports, the aircraft within each category are operated differently and have various needs; therefore, to reduce the number of LOC accidents in GA, each aircraft certification category needs to be addressed differently. The words found within each of the text mining clusters have indicated the emphasis areas where additional training, technology, or awareness should be placed to reduce LOC accidents. As seen in Table 3, the CAR 3 airplanes have, on average, the largest number of hours on the airframe; however, the average pilot flight times do not differ substantially among any of the categories. As suggested in the literature, retrofitting these older airplanes to take advantage of new technologies might help in the reduction of LOC accidents. Based on the clusters of words revealed in the text mining analysis, the areas of emphasis to reduce LOC accidents among CAR 3 airplanes should be: (a) avoiding VFR flight into IMC, (b) aeronautical decision making, (c) preflight planning, and (d) traffic pattern work, especially during instructional flights. To reduce LOC accidents among Part 23 airplanes, the areas of emphasis should be: (a) traffic pattern work, especially during instructional flights, and (b) spatial disorientation in instrument conditions. To reduce LOC accidents among the E-AB airplanes, the areas of emphasis should be: (a) takeoff, (b) landings, (c) maneuvering flight, and (d) low altitude maneuvering. To reduce LOC accidents among the LSA airplanes, the areas of emphasis should include: (a) traffic pattern work, especially during instructional flights, and (b) maneuvering flight. Advocacy groups like Experimental Aircraft Association (EAA) and American Society for Testing and Materials (ASTM) could be approached to disseminate information and conduct specialized training for each particular category, such as E-AB and LSA.

The adoption of consensus standards for GA aircraft certification could be an appealing alternative. Applying consensus standards has the potential to simplify the retrofit of the legacy fleet of GA airplanes to encourage the installation of safety enhancements in a timely and economically viable way. As supported by the literature, a risk management 
approach should be taken to analyze whether the current certification regulations are actually an obstacle in installing safety enhancing technology into the GA fleet (GAJSC, 2012). Installing autopilots and AOA indicators on a certified airplane could cost between five to ten times more than installing these devices on an experimental airplane, which could represent between $10 \%$ and $50 \%$ of the average value of a GA airplane (GAJSC, 2012). The risks and benefits of installing autopilots and AOA indicators in older aircraft without a stringent, expensive, and time-consuming certification process should be assessed.

\section{References}

Aerospace Industries Association, General Aviation Manufacturers Association, Federal Aviation Administration. (2004). The FAA and industry guide to product certification. Retrieved from http://www.faa. gov/aircraft/air_cert/design_approvals/media/CPI_guide_II.pdf

ASTM. (n.d.). About ASTM International. Retrieved from http://www. astm.org/ABOUT/overview.html

ASTM. (n.d.). Committee F4 on general aviation aircraft. Retrieved from http://www.astm.org/COMMITTEE/F44.htm

Bowles, G. (2010). Small airplanes [PowerPoint slides]. Retrieved from http://www.faa.gov/news/conferences_events/2010_us_eu/conference_ materials/media/ComplexSmallAircraftGAMA.pdf

Committee on Aircraft Certification Safety Management. (1998). Improving the continued airworthiness of civil aircraft. Washington, DC: The National Academies Press.

FAA. (2009). Part 23-small airplane certification process study. Washington, DC: Federal Aviation Administration. Retrieved from http://www.faa.gov/about/office_org/headquarters_offices/avs/offices/ air/directorates_field/small_airplanes/media/CPS_Part_23.pdf

FAA. (2011a). Airmen transition to experimental or unfamiliar aircraft (Federal Aviation Administration Advisory Circular No. 90-109). Washington, DC: U.S. Government Printing Office.

FAA. (2011b). Part 23 reorganization ARC charter. Washington, DC: Federal Aviation Administration. Retrieved from http://www.faa.gov/ regulations_policies/rulemaking/committees/documents/media/Part 23Reorg.ARC.Cht.8-15-2011.pdf

Federal Aviation Administration. (2012). 14 CFR 1 Definitions and Abbreviations. Retrieved from http://www.gpo.gov/fdsys/granule/ CFR-2012-title14-vol1/CFR-2012-title14-vol1-part1/content-detail. html

FAA. (2013). 14 CFR: Aeronautics and Space. Washington, DC: U.S. Government Publishing Office.

Field, A. (2009). Discovering statistics using SPSS. Thousand Oaks, CA: Sage Publications.
GAJSC. (2012). Loss of control work group approach and landing. Frederick, MD: Aircraft Owners and Pilots Association. Retrieved from http://download.aopa.org/advocacy/130327safety-committee. pdf

GAMA. (2012). General aviation statistical databook and industry outlook. Washington, DC: General Aviation Manufacturers Association. Retrieved from http://www.gama.aero/media-center/industryfacts-and-statistics/statistical-databook-and-industry-outlook

GAO. (2012). General aviation safety: Additional FAA efforts could help identify and mitigate safety risks (Report No. GAO-13-36). Washington, DC: Author. Retrieved from http://www.gao.gov/assets/ 650/649219.pdf

Johnson, D. (n.d.). SLSA list. Retrieved from http://www.bydanjohnson. com/index.cfm? $\mathrm{b}=7$

McClellan, M. (2013, Feb.). How to check out in an E-AB. EAA Sport Aviation, 62(2), 53-57.

National Technology Transfer and Advancement Act of 1995, Pub. L. No. 104-113, 5 Stat. 552 (1996).

NTSB. (2012a). Review of U.S. civil aviation accidents, calendar year 2010 (National Transportation Safety Board Publication No. NTSB/ARA12/01). Washington, DC: U.S. Government Printing Office. Retrieved from http://www.ntsb.gov/investigations/data/Documents/ARA1201. pdf

NTSB. (2012b). The safety of experimental amateur-built aircraft (Safety Study Publication No. NTSB/SS-12/01). Washington, DC: U.S. Government Printing Office.

Nisbet, R., Elder, J., \& Miner, G. (2009). Statistical analysis and data mining applications (1st ed.). Burlington, MA: Elsevier.

Part 23 Aviation Rulemaking Committee. (2012). Regulatory structure working group summary and ASTM F44 committee guidelines. Unpublished manuscript.

Pompeo, M. (2013, May 6). [Letter to GAMA]. Copy sent to Part 23 ARC members.

Shetty, K., \& Hansman, J. (2012). Current and historical trends in general aviation in the United States (Report No. ICAT 2012-6). Cambridge, MA: MIT International Center for Air Transportation. Retrieved from http://dspace.mit.edu/bitstream/handle/1721.1/72392/ICAT\% 20REPORT\%20SHETTY.pdf

Soaring Safety Foundation. (n.d.). Current v. proficient. Retrieved from http://www.soaringsafety.org/prevention/aps3.htm

Stephens, C. (2012). Evolving GA to a data-driven and proactive process [PowerPoint slides]. Retrieved from http://www.docstoc.com/docs/ 126681694/Evolving-GA-Safety-to-a-Data-Driven-and-ProactiveProcess.

Teddie, C., \& Tashakkori, A. (2009). Foundations of mixed methods research: Integrating quantitative and qualitative approaches in the social and behavioral sciences. Thousand Oaks, CA: Sage Publications.

Wensveen, J. (2007). Air transportation: A management perspective. Brookfield, VT: Ashgate Publishing Group. 


\begin{tabular}{|c|c|c|c|}
\hline \multicolumn{4}{|l|}{ Appendix } \\
\hline \multicolumn{2}{|c|}{ Definition of Terms } & ANOVA & Analysis of Variance \\
\hline \multirow{5}{*}{14 CFR Part 23} & Part 23 within Title 14 of the Code of Federal & $\mathrm{ARC}$ & Aviation Rulemaking Committee \\
\hline & Regulations contains airworthiness and & ASME & American Society for Mechanical Engineers \\
\hline & certification standards for airplanes in the & ASTM & American Society of Testing and Materials \\
\hline & $\begin{array}{l}\text { normal, utility, and aerobatic categories, with } \\
\text { a maximum certificated takeoff weight of }\end{array}$ & ASTM F44 & $\begin{array}{l}\text { American Society of Testing and Materials } \\
\text { Chapter F44 }\end{array}$ \\
\hline & 12,500 pounds or less (FAA, 2012). & BRS & Ballistic Recovery Parachutes \\
\hline \multirow[t]{3}{*}{ Aircraft } & $\begin{array}{l}\text { Device that is used or intended to be used for } \\
\text { flight in the air, including airplanes, }\end{array}$ & CACSM & $\begin{array}{l}\text { Committee on Aircraft Certification Safety } \\
\text { Management }\end{array}$ \\
\hline & helicopters, and gliders, among others (FAA, & CAR & Civil Air Regulation \\
\hline & 2012). & CAR 3 & Civil Air Regulation 3 \\
\hline \multirow[t]{4}{*}{ Airplane } & Engine-driven fixed-wing aircraft, heavier- & CFI & Certified Flight Instructor \\
\hline & than-air that are supported in flight by the & CFIT & Controlled Flight into Terrain \\
\hline & dynamic reaction of the air against its wings & CFR & Code of Federal Regulations \\
\hline & (FAA, 2012). & CPS & Certification Process Study \\
\hline \multirow{10}{*}{$\begin{array}{l}\text { Certification } \\
\text { Basis }\end{array}$} & The certification basis identifies the & DER & Designated Engineering Representative \\
\hline & applicable standards to which the applicant & DoD & Department of Defense \\
\hline & must show compliance. It also includes the & DOT & Department of Transportation \\
\hline & need for special conditions, exemptions, and & EAA & Experimental Aircraft Association \\
\hline & equivalent safety findings, if any. An issues & $\mathrm{E}-\mathrm{AB}$ & Experimental-Amateur Built \\
\hline & list should be included to highlight those & EAC & Eclipse Aviation Corporation \\
\hline & $\begin{array}{l}\text { special requirements needing resolution and } \\
\text { other areas that may be significant, even } \\
\text { though they may not warrant a special }\end{array}$ & EIA/GEIA & $\begin{array}{l}\text { Electronic Industries Alliance/Government } \\
\text { Electronics and Information Technology } \\
\text { Association }\end{array}$ \\
\hline & condition, exemption, or equivalent safety & E-LSA & Experimental-Light Sport Aircraft \\
\hline & finding (Aerospace Industries Association & FAA & Federal Aviation Administration \\
\hline & [AIA], GAMA \& FAA, 2004). & FAR & Federal Aviation Regulations \\
\hline \multirow{4}{*}{$\begin{array}{l}\text { Entry-level } \\
\text { Airplane }\end{array}$} & In the context of this study, entry-level & FAWG & Future of Aerospace Working Group \\
\hline & aircraft or airplane means an aircraft that one & GA & General Aviation \\
\hline & might use or acquire in the beginning of his or & GAJSC & General Aviation Joint Steering Committee \\
\hline & her flying experience. & GAMA & General Aviation Manufacturers Association \\
\hline \multirow{6}{*}{$\begin{array}{l}\text { General } \\
\text { Aviation }\end{array}$} & All non-military aviation operations other & GAO & Government Accountability Office \\
\hline & than scheduled air services and air transport & GARA & General Aviation Revitalization Act \\
\hline & for remuneration or hire. These operations & GDP & Gross Domestic Product \\
\hline & include flight instruction, business, personal, & GPS & Global Positioning System \\
\hline & and aerial work among others (Wensveen, & ICAO & International Civil Aviation Organization \\
\hline & 2007). & ICAT & International Center for Air Transportation \\
\hline \multirow{6}{*}{$\begin{array}{l}\text { Pilot } \\
\text { Proficiency }\end{array}$} & "[T] he state of performing a given skill with & IEEE & Institute of Electrical and Electronic \\
\hline & expert correctness." (Soaring Safety & & Engineers \\
\hline & Foundation, n.d., para. 2) & IFR & Instrument Flight Rules \\
\hline & & IMC & Instrument Meteorological Conditions \\
\hline & & IPC & Institute for Printed Circuits \\
\hline & & ISO & International Organization for \\
\hline \multirow{2}{*}{\multicolumn{2}{|c|}{ List of Acronyms }} & & Standardization \\
\hline & & LOC & Loss of Control \\
\hline 14 CFR & Title 14 of the Code of Federal Regulations & LSA & Light Sport Aircraft \\
\hline $\mathrm{AC}$ & Advisory Circular & LTSP & Light-Sport Special Category (NTSB \\
\hline $\mathrm{ACO}$ & Aircraft Certification Office & & database variable name) \\
\hline \multirow[t]{2}{*}{ ACPRR/ARC } & Aircraft Certification Process Review and & MIDO & Manufacturing Inspection District Office \\
\hline & Reform/Aviation Rulemaking Committee & Mil-specs & Military-specifications \\
\hline $\mathrm{AD}$ & Airworthiness Directive & MSR & Military Specifications Reform \\
\hline \multirow[t]{2}{*}{ ADS-B } & Automatic Dependent Surveillance- & NPRM & Notice of Proposed Rulemaking \\
\hline & Broadcast & NTSB & National Transportation Safety Board \\
\hline AIA & Aerospace Industries Association & NTTAA & National Technology Transfer and \\
\hline \multirow[t]{2}{*}{ AIAA } & American Institute of Aeronautics and & & Advancement Act \\
\hline & Astronautics & ODA & Organization Delegation Authorization \\
\hline AIR & Aircraft Certification Service & OMB & Office of Management and Budget \\
\hline ANCOVA & Analysis of Covariance & Part 23 & 14 CFR Part 23 \\
\hline
\end{tabular}


Part 25

PMA

SAE

SFAR

S-LSA

SPE

SPL

SPR

SPS

SPSS
14 CFR Part 25

Parts Manufacturing Approval

Society of Aerospace Engineers

Special Federal Airworthiness Regulation

Special-Light Sport Aircraft

Special Category Experimental (NTSB

database variable name)

Special Category Limited (NTSB database variable name)

Special Category Restricted (NTSB database variable name)

Special Flight (NTSB database variable name)

Statistical Product and Service Solutions previously Statistical Package for the Social Sciences
SPV

SSF

STA

STC

STN

STT

STU

TSOA

UNK

USITC

VFR
Special Provisional

Soaring Safety Foundation

Standard Category Aerobatic (NTSB

database variable name)

Supplemental Type Certificates

Standard Category Normal (NTSB database variable name)

Special Transport (NTSB database variable name)

Standard Category Utility (NTSB database variable name)

Technical Standard Order Authorization Unknown (NTSB database variable name)

United States International Trade

Commission

Visual Flight Rules 